
\title{
$\angle S$ Research Square \\ Drivers of Greenhouse Gas Emissions from Standing Dead Trees in Ghost Forests
}

Melinda Martinez ( $\nabla$ mmarti13@ncsu.edu )

North Carolina State University https://orcid.org/0000-0001-6652-9220

Marcelo Ardon

North Carolina State University

\section{Research Article}

Keywords: carbon dioxide (CO2), methane (CH4), nitrous oxide (N2O), freshwater, wetlands, ghost forests

Posted Date: February 23rd, 2021

DOI: https://doi.org/10.21203/rs.3.rs-231981/v1

License: (c) (i) This work is licensed under a Creative Commons Attribution 4.0 International License. Read Full License 


\section{Abstract}

Coastal freshwater forested wetlands are rapidly transitioning from forest to marsh, leaving behind many standing dead trees (snags) in areas often called 'ghost forests'. Snags can act as conduits for soil produced greenhouse gases $(\mathrm{GHG})$ and can also be sources as they decompose. Thus, snags have the potential to contribute GHGs to the atmosphere, but emissions are not well understood. We assessed GHG emissions (carbon dioxide - $\mathrm{CO} 2$, methane - $\mathrm{CH} 4$, and nitrous oxide - $\mathrm{N} 2 \mathrm{O}$ ) from snags and soils in five ghost forests along a salinity gradient on the coast of North Carolina, USA. Mean ( \pm SE) soil GHG fluxes $(416 \pm 44 \mathrm{mg}$ CO $2 \mathrm{~m}-2 \mathrm{hr}-1,5.9 \pm 1.9 \mathrm{mg} \mathrm{CH} 4 \mathrm{~m}-2 \mathrm{hr}-1$, and $0.1 \pm 0.06 \mathrm{mg} \mathrm{N} 20 \mathrm{~m} \mathrm{-2} \mathrm{hr}-1$ ) were $\sim 4$ times greater than mean snag GHGs $(116 \pm 15 \mathrm{mg} \mathrm{CO} 2 \mathrm{~m}-2 \mathrm{hr}-1,0.3 \pm 0.09 \mathrm{mg} \mathrm{CH} 4 \mathrm{~m}-2 \mathrm{hr}-1$ , and $0.04 \pm 0.009 \mathrm{mg} \mathrm{N} 20 \mathrm{~m}-2 \mathrm{hr}-1$ ). Hydrological conditions and salinity influenced soil GHG fluxes between the two field campaigns, but snags were less predictable and more variable. Snag and soil $\mathrm{CO} 2$ /N 20 fluxes were influenced by similar environmental parameters. The drivers for soil and snag $\mathrm{CH} 4$ however, were often not the same and at times oppositely correlated. Our results illustrate the need to include tree stem GHGs in regional and global budgets.

\section{Full Text}

Due to technical limitations, full-text HTML conversion of this manuscript could not be completed. However, the latest manuscript can be downloaded and accessed as a PDF.

\section{Figures}
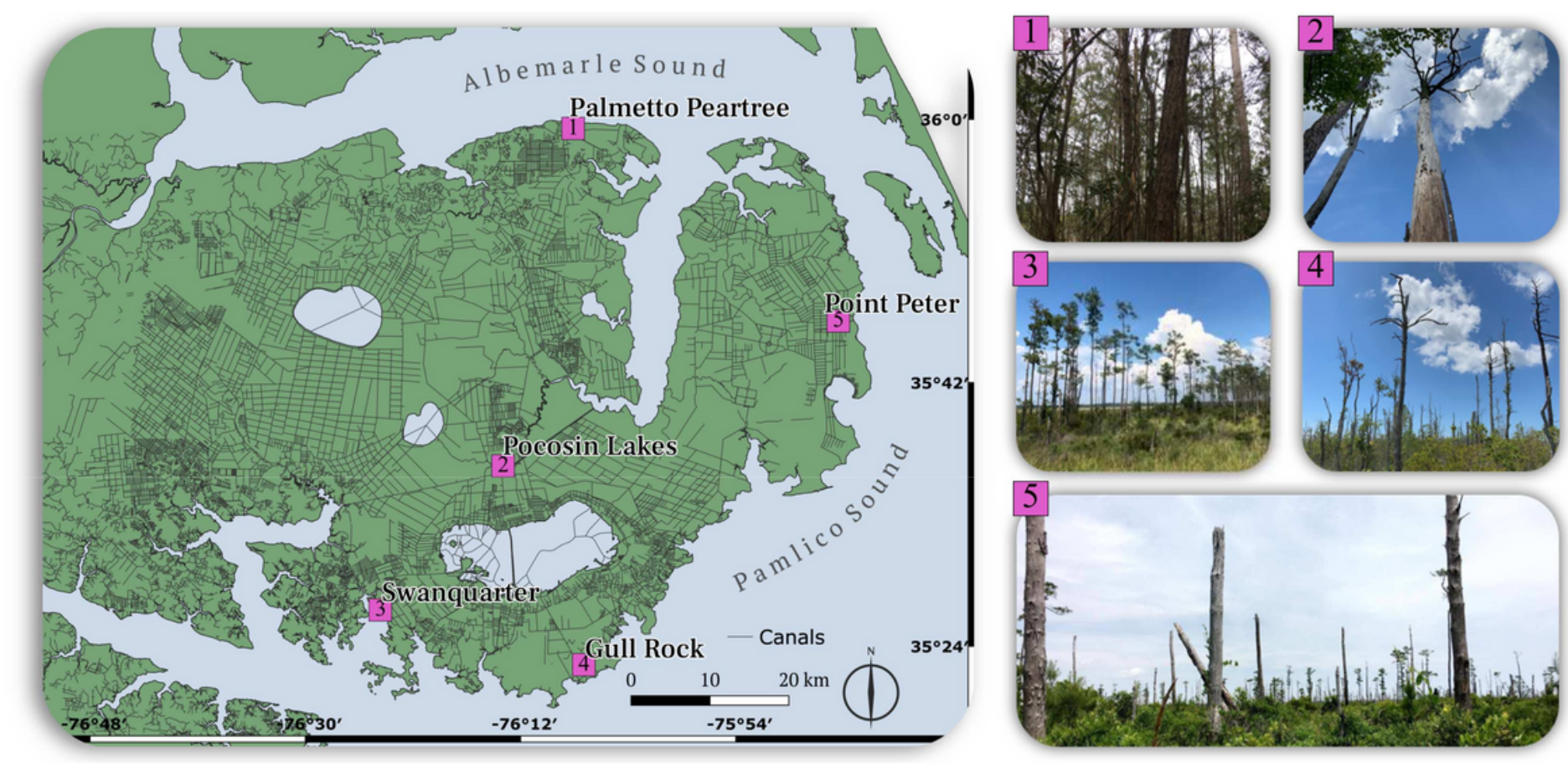

Figure 1 
Location of study in North Carolina, USA. Photos (right) shown of study areas with corresponding numbers on map (left). 1-1 Palmetto Peartree Preserve (PPP); 1-2 Pocosin Lakes National Wildlife Refuge (PC); 1-3 Swanquarter National Wildlife Refuge (SQ); 1-4 Gull Rock Game Lands (GR); 1-5 Point Peter Rd located within Alligator River National Wildlife Refuge (PP) Note: The designations employed and the presentation of the material on this map do not imply the expression of any opinion whatsoever on the part of Research Square concerning the legal status of any country, territory, city or area or of its authorities, or concerning the delimitation of its frontiers or boundaries. This map has been provided by the authors. 


\section{9}

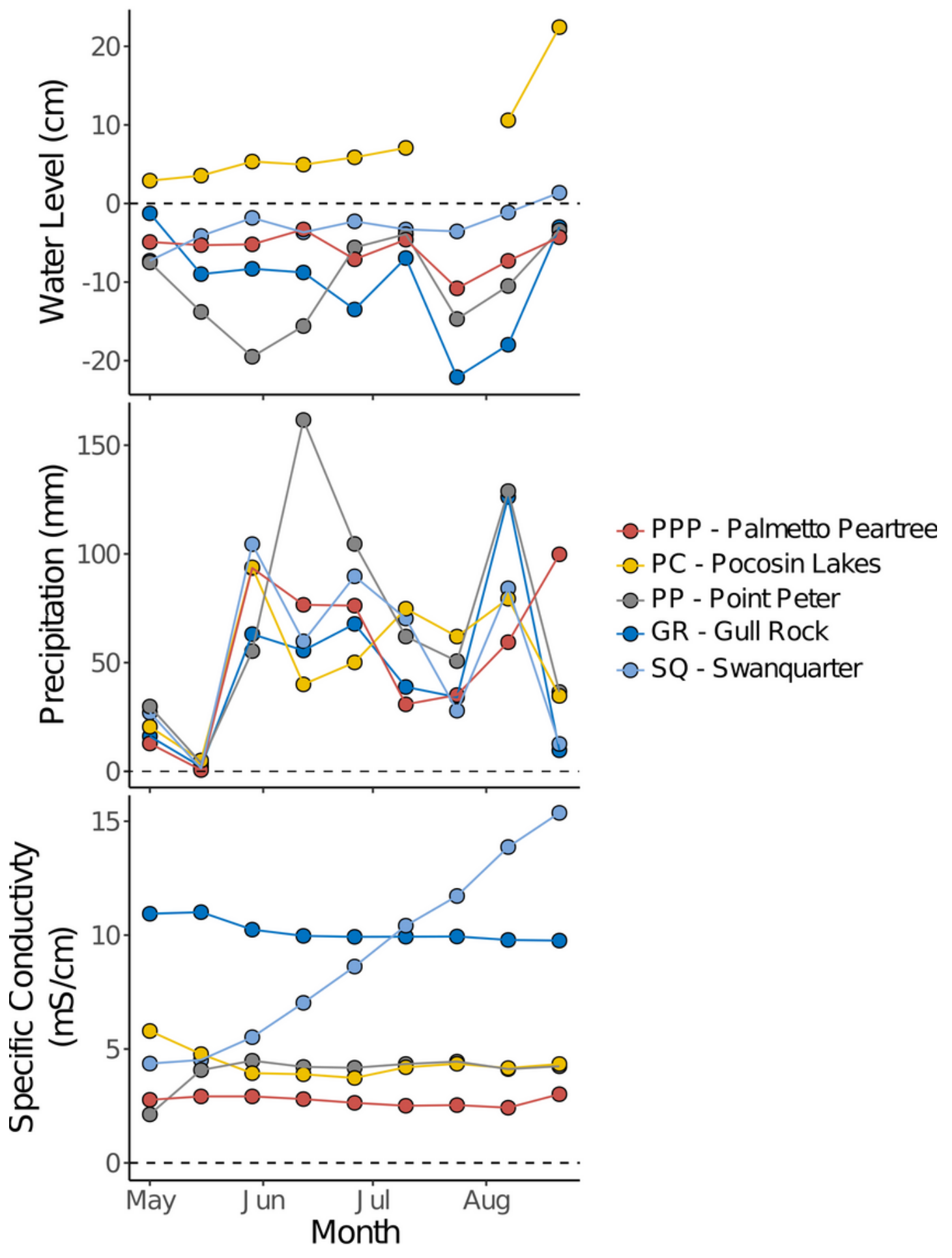

Figure 2

Median biweekly water dynamics for each site during the 2019 growing season. Precipitation is cumulative for each 2-week interval. Water level data at PC was not logged from Jun 15 - Aug 1 due to logger malfunction 
a)
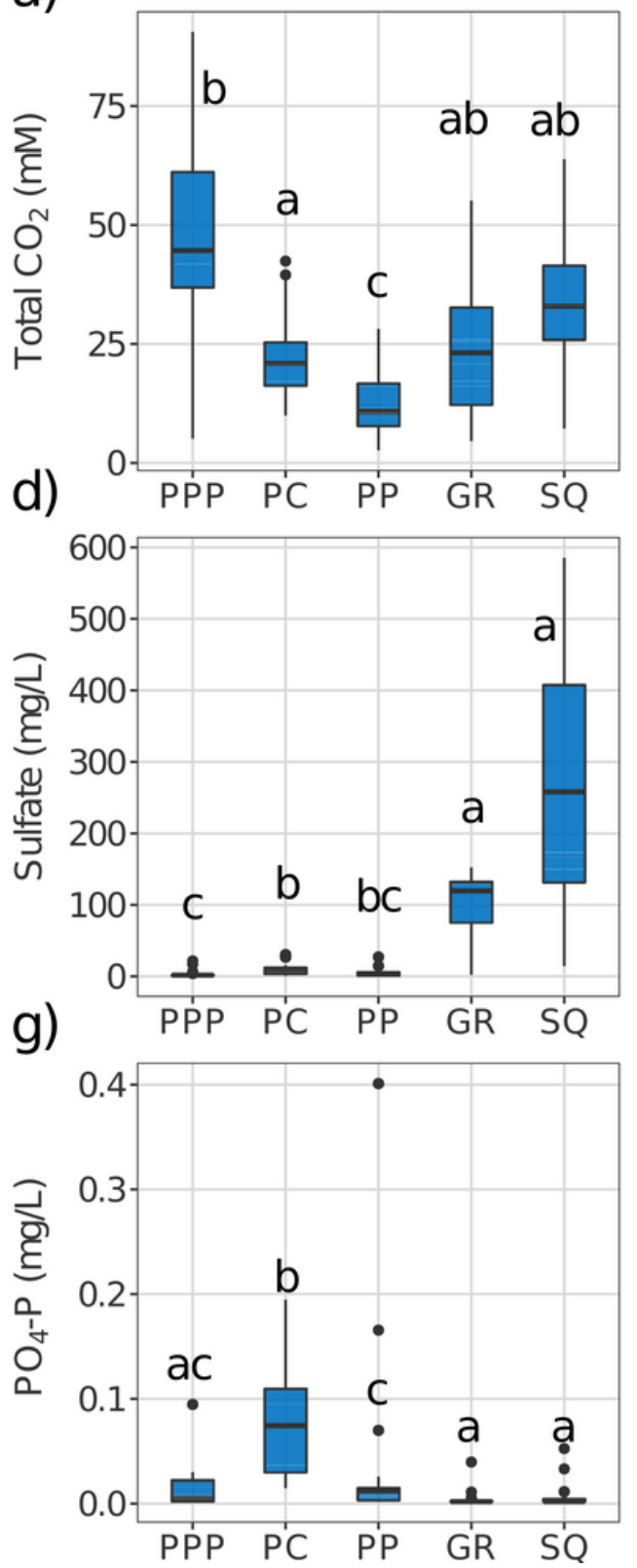

b)
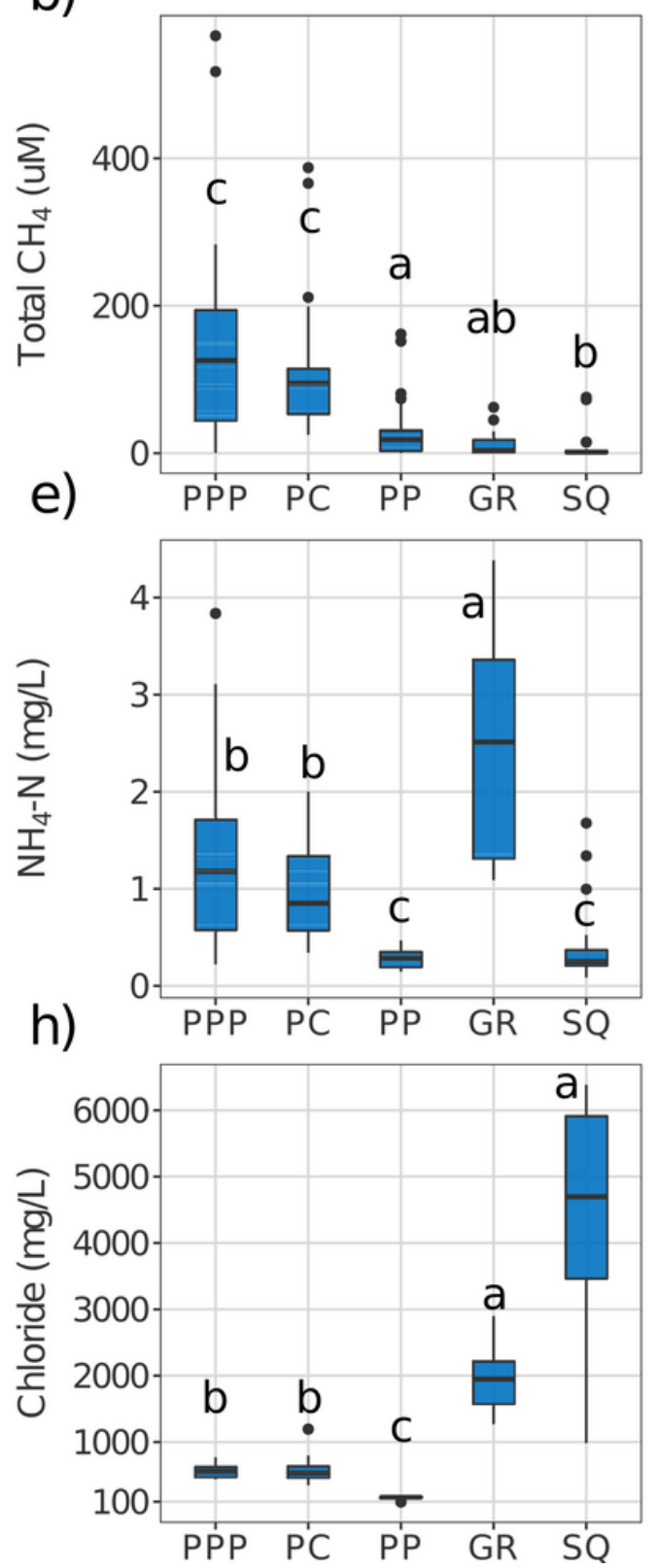

c)
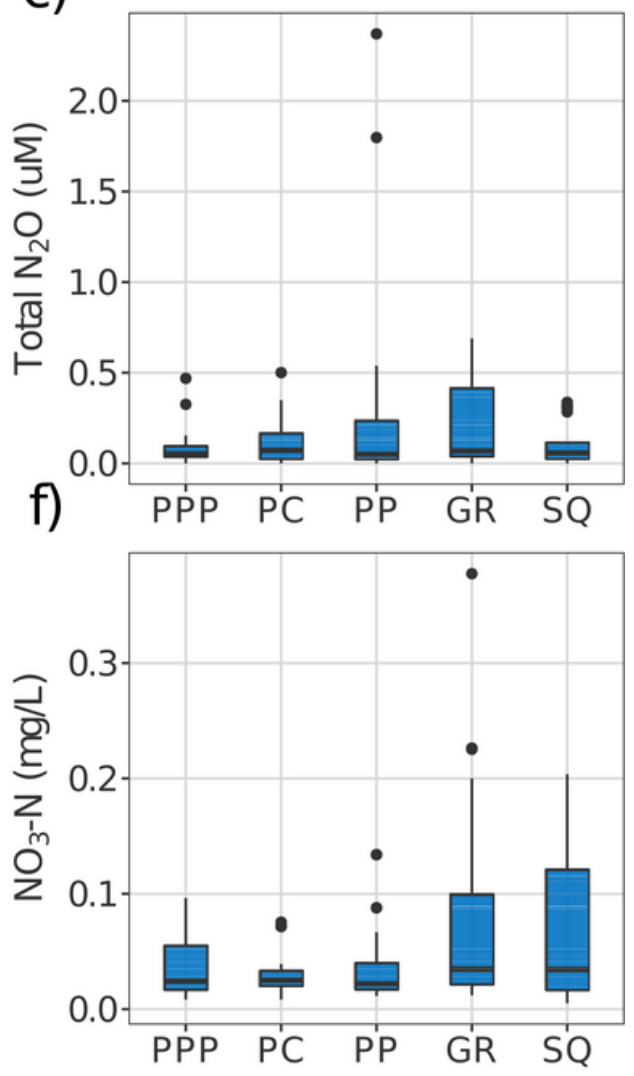

Figure 3

Porewater chemistry and greenhouse gas concentrations for each site from 2019 only (15 and $30 \mathrm{~cm}$ combined). Solid line represents median, whiskers represent 5 th and 95th percentiles, and dots are outliers. Different letters show significant differences between sites $(p<0.05)$ 


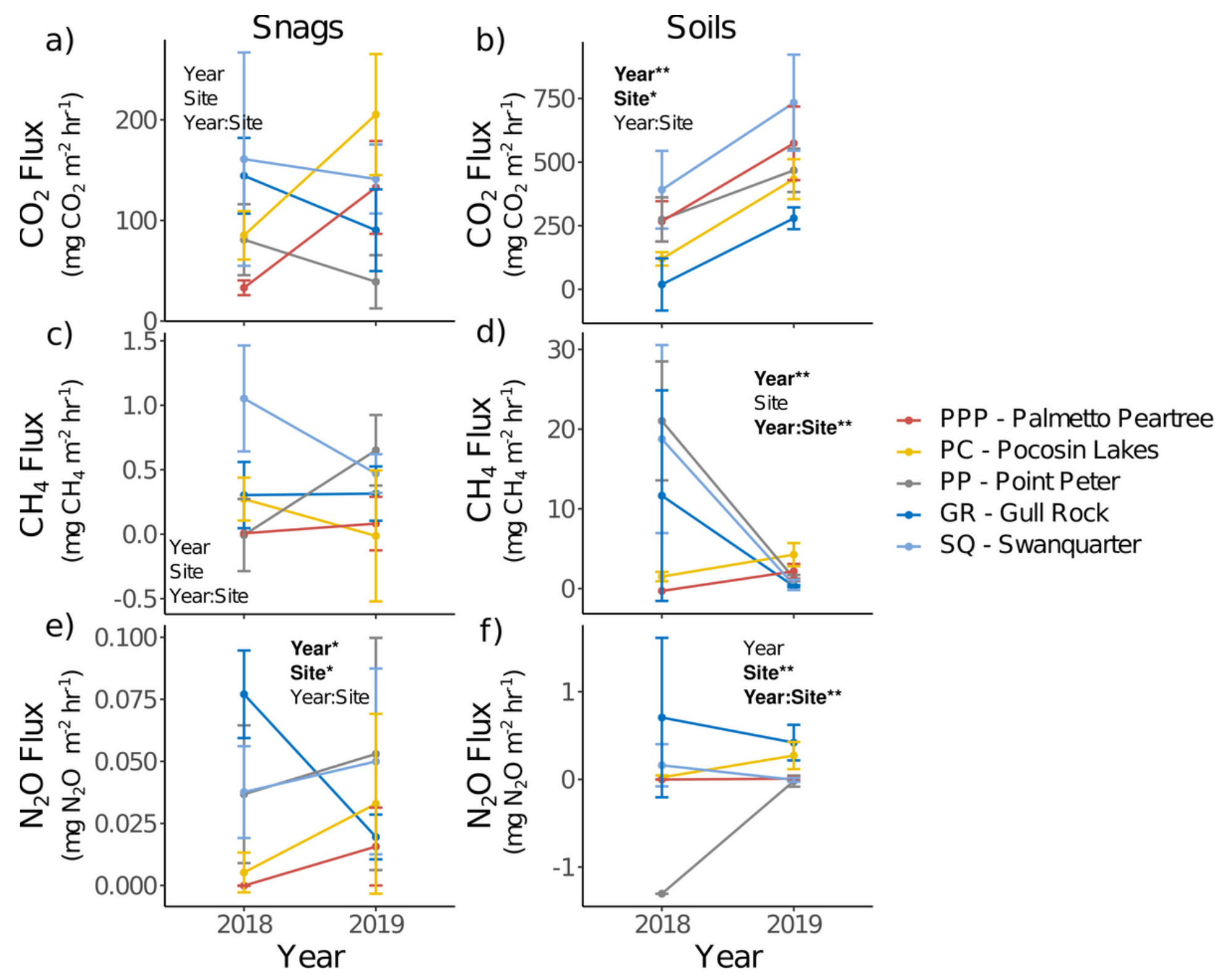

Figure 4

Mean $\left( \pm\right.$ SE) GHG fluxes for tree and soil chambers by year and site. Significant factors are in bold; ( $\left.{ }^{\star *}\right)$ indicates $p<0.05$ and $(*)$ indicates $p<0.1$. Note different scales between respective tree and soil GHG fluxes 


\section{Snags}

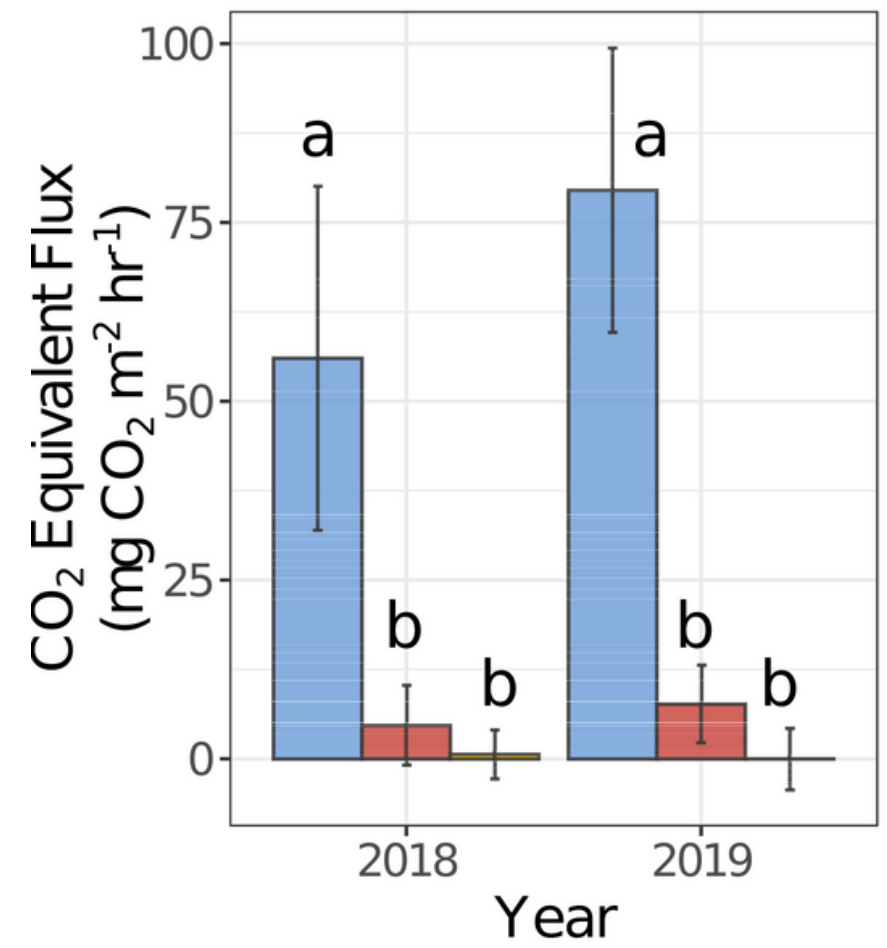

Soils

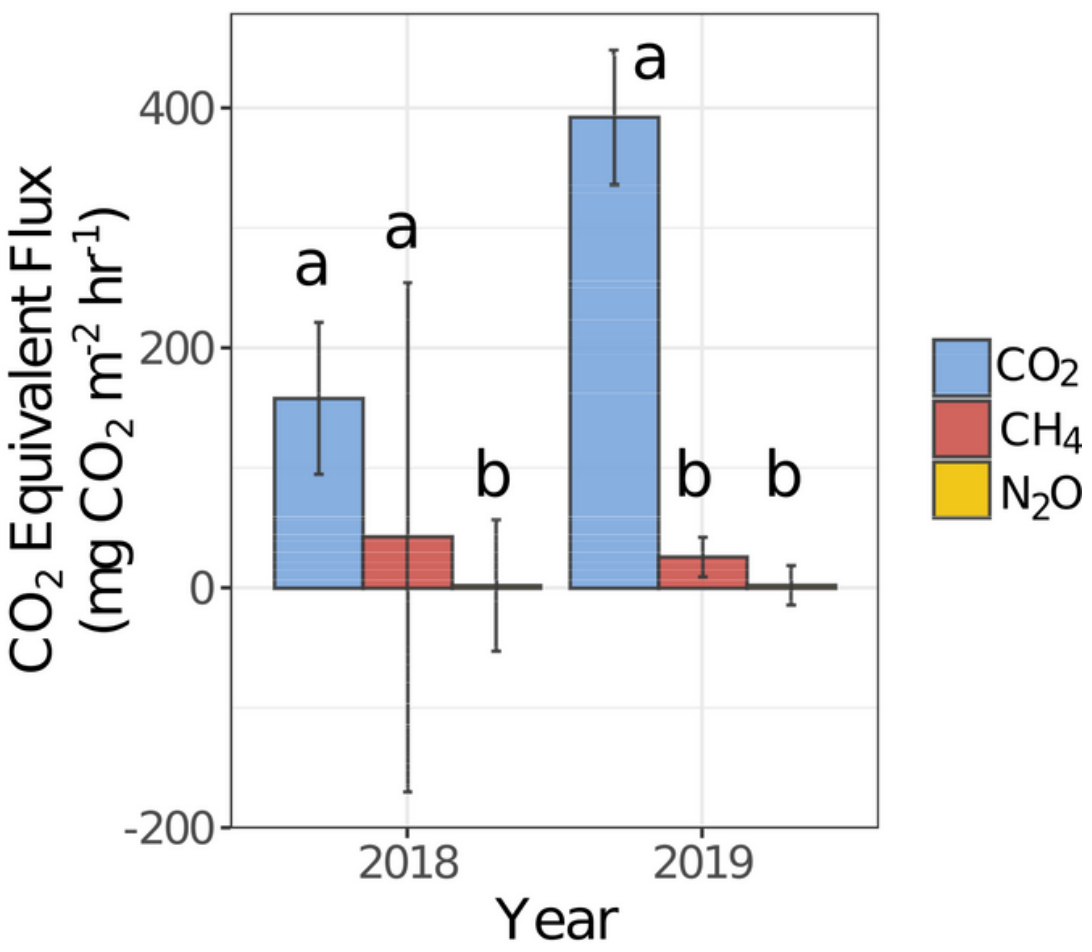

Figure 5

Median ( \pm SE) $\mathrm{CO} 2$ equivalent flux $(\mathrm{CO} 2, \mathrm{CH} 4 \times 40, \mathrm{~N} 2 \mathrm{O} \times 298)$ for soils and tree fluxes by year. Note different scales between soils and tree fluxes. Different letters indicate significant differences between CO2 equivalent GHGs within respective year

\section{Supplementary Files}

This is a list of supplementary files associated with this preprint. Click to download.

- ESMMMartinez20210208.pdf 